\title{
Cultural Audits as Tools for Enabling Processes of Change in the NHS
}

\author{
Mahima Mitra (University of Oxford) \\ Máire Brankin (Oxford Executive Coaching Ltd.) \\ Paul Brankin (Green Templeton College, Oxford \& Oxford Executive Coaching Ltd.)
}

\begin{abstract}
The organisations that make up the NHS are subject to frequent change, either as a result of top-down restructuring, or of internal reorganisation. There is considerable evidence that one key to the success of such change lies in understanding the culture of the organisation that is undergoing change, with various authors suggesting that cultural audits be undertaken as a means of achieving this. Cultural audits as described in current literature can be complex, time-consuming and resource-intensive, which may be one reason that, in our experience, they are not often conducted. This paper describes a method of assessing the culture of an organisation rooted in ethnographic principles from Social Anthropology which is relatively simple, can be carried out in a few weeks, and requires a manageable level of resource. The method has been used to good effect in a number of NHS organisations. An example of its successful application is presented. The authors hope that this method might become widely adopted, leading to a higher success rate for change programmes in the NHS.
\end{abstract}

\section{Introduction}

The organisations that make up the NHS are undergoing frequent change, either as a result of top-down restructuring, or of internal reorganisation. A number of challenges underly these changes. The need to provide good quality yet cost-effective services is one. A greater need for integration between different service providers (e.g. government, private, charity), sectors (e.g. health and social care), professionals (e.g. clinicians, allied health practitioners, 
nurses), and modes of service provision (hospital and GP-based, telephonic, and electronic), is another. Enabling doctors and managers to work together collaboratively, especially at the senior leadership levels (Mitra, Dopson, Brankin \& Hoff, 2017; Powell \& Davies, 2016), and creating the structures and processes to support them in doing so, is a third challenge.

There is considerable evidence that one key to making successful change lies in understanding the culture of the organisation that is going to be the recipient of change (Davies, Nutley \& Mannion, 2000; May, 2014; Sanchez, 2011; Schein, 2010; Wilkins, 1983). Culture shapes the "overall ethos of an organization...[and] affect[s] the perceptions and behaviour of [its] employees" (Fletcher \& Jones, 1992, p.30). The form and shape taken by the organisation, as it evolves, can either confound and clash with its existing culture, or develop more harmoniously with it, thereby leading to successful transformation.

Audits present one way of examining an organisation's culture (Armenakis, Brown \& Mehta, 2011; Castellano \& Lightle, 2005; Fletcher and Jones, 1992; Jung, Scott et al, 2009; McHugh, 1998; Schorg, Raiborn \& Massoud, 2004; Testa \& Sipe, 2013). However, undertaking them is understood as being an expensive process that is time-, people- and resource-intensive (Castellano \& Lightle, 2005; Schorg et al., 2004; Scott, Mannion, Davies \& Marshall, 2003). Extant literature indicates that the NHS' use of cultural assessment tools to support clinical governance activity is scant; however there is an interest in using such audits to study board-level cultures (Mannion, Davies, Konteh et al., 2008). Nonetheless, such examinations have not been reported in the literature thus far, even though their significance has been discussed (Catellano \& Lightle, 2005; Lightle, Baker and Castellano, 2009). There are also few existing guidelines that go beyond discussing the need for undertaking cultural audits, to describing, in detail, how such an exercise might be practically undertaken.

This paper describes a methodology for conducting cultural audits that is relatively simple, inexpensive, and possible for a small team to complete in a few weeks' time. The 
method is rooted in ethnographic principles from Social Anthropology, and presented as a practical tool that can be easily understood and applied. The approach has been refined and tested over a period of 20 years by two of the co-authors (PB, MB) who have many years of organisational development experience with a number of NHS bodies. We present, first, an overview of the method, alongside some practical considerations. We go on to illustrating to what purpose, and in what ways, this method has been utilized within the context of NHS organisations by presenting a case study that draws upon our work with several organisations over the years. The case study also showcases some of the results that the application of such audits has contributed towards achieving.

\section{The Cultural Audit}

Cultural Audits encompass a variety of quantitative and qualitative tools for measuring an organisation's culture (Jung, Scott et al, 2009). The methodology described here is designed to obtain an objective assessment of how an organisation is perceived by its members and other stakeholders. Our basic premise is that people and their relationships are the overriding factor in the success or failure of an organisation. However, attempting to change people's behaviour without changing the environment in which they function is not likely to lead to sustained transformation in the long run.

An audit can provide the time and space to check that unexamined tensions are not being disruptive to the collaborative working of an organisation, and can be particularly useful after periods of intense activity and change. These may include both internal changes, as well as inter-organisational mergers where, for example, diverse cultures in health and social care are brought together within the context of a primary care organisation. The culture of the group may be well understood by its members, but hard to define and change. An audit, in combination with an appropriate organisational development programme, can help shape the culture that organisational members hope to belong to, and which leads to 
efficacious change. Such an exercise can be conducted either before a period of change begins (for instance, when organisations are considering mergers), or while the transformation process is underway.

A typical audit should elicit views from a representative group of organisational staff and external stakeholders to get a snapshot of key issues, including a map of the existing emotional and interpersonal climate. The rationale is to hold up a 'mirror' in front of participants, and to enable them to collectively acknowledge what they might already individually know.

Active board-level sponsorship is the first step in undertaking an audit as it both maintains and enhances the usefulness and validity of the exercise for the organisation seeking development and change. It is also critical that the design phase be preceded by meetings with the commissioning organisation to identify the issues needing exploration.

\section{Research design \& methodology}

Our methodology draws upon ethnographic techniques from Social Anthropology; which undertakes a systematic study of people, cultures and contexts, through a first-hand observation of social phenomena as unfolding in the natural environment. A key requisite of this approach is to take an unprejudiced position when engaging in the audit. In keeping with an Anthropological standpoint, this method employs a primarily qualitative and exploratory approach, rather than one that tests a pre-determined hypothesis. The aim is to discover 'what is going on' rather than 'what is going wrong'. We believe that such an approach is more suited to "getting beyond the public faces presented by...institutions" (Scott et al., 2003, p.939) and exploring individual beliefs and opinions.

The primary tool is a series of face-to-face, semi-structured interviews with a representative sample (typically 10\%) of the staff of the organisation, lasting approximately one hour, undertaken in the workplace. Although participants are asked the same set of questions, these are deliberately open-ended to encourage them to talk about those issues 
that are most important to them. When organisation-wide sentiments need to be captured, web surveys are administered, using platforms such as 'SurveyMonkey'.

Staff interviews are accompanied by interviews with external stakeholders, typically commissioners of the services provided by the organisation being audited, and staff in related organisations.

A key requisite for success is to assure participants at the start of the interview that the audit is confidential and that anything they say will be reported in a way that is nonattributable. It is trust in the confidential nature of the audit that enables participants to be frank and open about the way they experience their organisation. To further encourage openness in the audit, it is always made clear that the audit is to be used only within the organisation for development purposes and is not used to 'blame and shame' either internally or externally.

\section{Participant selection and sampling}

Data is collected from all levels, roles and professions in the organisation. These will include senior executives and board members, middle managers, doctors, other clinicians, other professionals (e.g., social services) and administrators. The sample is further refined to provide a balance of other characteristics, including gender, seniority, job role, and number of years with the organisation.

Depending on the wishes of the sponsor and practical considerations, sample selection varies between self-selection (based, e.g., on a 'call to participate' sent out by the organisation to all staff), and the drawing of a representative sample of participants by the auditing body, as described above. External stakeholders are nominated for participation by the organisational Board members sponsoring the audit exercise.

The total number of participants inevitably varies depending on the size of the organisation and the goal of the audit exercise; however the aim is always to include around 
$10 \%$ of all staff. A smaller percentage of participants could be considered for larger organisations by selecting a more carefully managed, representative sample.

\section{Data collection}

Open-ended interviews are the primary tool for collecting data from participants. The significance of asking open-ended questions lies in their ability to unlock unspoken assumptions that are situated somewhere between the more visible organisational artefacts, and the less discernable espoused values of the individuals working within it (Schein, 2010).

The themes around which interview questions are structured will vary, however, they will largely focus on the interpersonal and emotional climate of the organisation, the perceived performance of the organisation against its goals, the performance of individuals in the organisation against organisational goals, the quality of relationships both within the organisation and externally, and areas for performance development.

The drafting of interview questions is critical to the success of audits. These should be few in number (5 to 10$)$, with wording that does not lead participants on in any particular direction. Questions must be broad enough to accommodate for a variety of responses, yet narrow enough to focus on cultural issues (see Box 1 for two examples).

Another key component relates to the interviewer's experience with 'reflexive listening' participants must be given the time and space to hear themselves talk and think during the interview. This facilitates personal awareness, and allows for 'creative conversations' about organisational culture to take place.

<insert Box 1 here>

An audit might use additional techniques to supplement and triangulate interview data. A particularly useful tool in this regard is the unstructured observation, which may be 
conducted when visiting participants' workplace for interviews. Such observations can be particularly helpful for understanding the physical and emotional environment, and to see how relationships in the organisation work in practice.

\section{Data analysis}

Interview responses are recorded by hand, and analysed in a number of stages outlined below. These are described sequentially, but, in practice, are often followed interchangeably, in parallel.

Stage 1 entails reading each manuscript and highlighting emerging themes against each question. The decision on what to include as a theme will be subjective. However, each manuscript is read by two reviewers in an effort to avoid unconscious bias.

In Stage 2, a list of themes is extracted from each manuscript as it is read and highlighted in turn, using standard phraseology, and based upon participant quotes and phrases that that most closely capture the relevant theme.

In Stage 3, the manuscripts are read a second time to create an overall record of the number of occurrences of each theme, listed in decreasing order of frequency. Generally, no theme is reported unless it has been mentioned by a significant number of participants. This procedure is also a key factor in ensuring anonymity for participants.

In Stage 4, a typically short synthesis or summary statement that captures the overall finding for each theme is identified from the interview manuscripts. In our experience these, often widely-used, statements within organisations (e.g. 'Management never listens') can capture a real sense of how the organisation sees itself.

\section{Outcomes}

The 'outcome' of an audit exercise is a report that sets out a qualitatively rich, well-balanced and objective view of the organisation studied. The first part of the report captures the recurring themes for each question asked, with some indication of how frequently the theme was mentioned during the interviews. It is crucial that this section presents the 
shared views of the participants in their own words rather than the views and interpretations of the auditors.

The second section of the report is a summary of findings, combined with any personal observations and experiences the interviewers had when carrying out the audit. These will include, e.g., how auditors experienced the organisation's physical and emotional environment (e.g. spacious, relaxed, friendly, well-organised), and the apparent emotional state of the people interviewed (e.g. happy, enthusiastic, enjoying their work, collaborative).

The aim of the audit report is to facilitate reflection and enable an organisation to move swiftly towards understanding precisely what needs to change in order for it to perform better. The auditing body must provide a robust and honest account of participant views, without compromising their anonymity. Typically the report is discussed first with the management team that commissioned the audit and, once reviewed, circulated to all staff within the organisation. Timely feedback is critical to the success of any audit exercise (Mannion, Davies, Konteh, et al, 2008).

A cultural audit may be followed by workshops with all staff, as well as away days and executive coaching programmes with management and other teams, as part of an overall organisation development programme emerging from audit results.

We now present a case study, based on our work with various NHS bodies over the years, to illustrate to what purpose, and in what ways, the cultural audit tool may be applied for effecting change programmes in NHS organisations.

\section{Southtown Specialty: A Story of Organisational Change}

Southtown Speciality is part of a large NHS Foundation Trust providing a range of services to the public. Placing the patient at the forefront of service provision, and providing high quality care through skilled and committed staff have always been part of its organisational 
identity. These factors have also contributed to Southtown's success as an organisation in the past.

Recent changes, particularly an increase in demand within the context of shrinking resources, have led to a reorganisation of the structures of the services at Southtown. In this context, the newly appointed Director of Services commissioned a Leadership Development Programme for its doctors. To understand the organisational environment in which the doctors were working, it was agreed that a cultural audit be undertaken as the first step in this process. It was agreed that the audit would include three elements:

- A web-based survey open to all staff $(n=200)$

- Face-to-face interviews with a self-selected group of managers and staff from a cross-section of roles, genders, and service lengths $(n=32)$

- Telephone interviews with external commissioners and partner organisations, nominated by the organisation $(n=12)$.

The resulting report highlighted a number of findings. The organisation was reported internally and externally as providing high-quality care for many of its patients and the dedication and skill of its staff were regarded as real strengths. However, many staff felt worried, stressed and unsupported, and internal and external communication was reportedly poor. The recent re-organisation was said to be a 'work in progress', leadership within the organisation was seen as in need of strengthening, and participants wanted the doctors to operate more effectively as a team.

Once shared with the Director of Services, these findings were disseminated among staff through a series of six workshops where participants also explored how they might help in improving services. This was supplemented by leadership and team development coaching sessions with both clinical and non-clinical leaders. 
Follow-up meetings nine months after the audit was conducted revealed a number of positive developments: staff felt re-engaged, and perceived the management, especially clinical leaders, as working better together, and being more actively involved in the organisation. Communication was better all round. The re-organisation was largely complete and there was optimism that the organisation would continue to improve.

\section{Conclusion}

An organisation that wishes to assess its suitability for an audit might start by asking "whether [its] current culture is keeping pace with the demands of its operating environments and challenges" (Sanchez 2011, p.31). It must then proceed to identifying the potential scenarios where its culture can reveal itself, such as, when employees change roles, subcultures clash, and top management teams make decisions that change the direction of the organisation (Wilkins, 1983).

This paper has described a straightforward and easy-to-follow method, rooted in ethnographic principles, for assessing an organisation's culture. An audit using this method can be carried out in a few weeks and requires a manageable level of resource. Active Board-level sponsorship is a necessary first step in this exercise. Although there is no one 'best' way of conducting a cultural audit, this method addresses some of the limitations reported in other tools, including: "difficulties around understanding and using instruments; lack of senior management support; credibility and sensitivity to local needs and contingencies", and lack of timely feedback (Mannion, Davies, Konteh, et al, 2008, p.135).

We hope this method will be helpful to those seeking to undertake a practical assessment of an organisation's culture before instituting change. It should encourage healthcare leaders to be cognizant of the role that culture can play in contributing to organisational 'success', and guide them in undertaking such an examination in a way that is more manageable and less daunting in the future. 


\section{Key Messages}

- An audit rooted in ethnographic principles can provide the time and space to check that unexamined tensions are not being disruptive to the collaborative working of an organisation. A key requisite of such an approach is to take an overall unprejudiced position when engaging in any analysis.

- Active board-level sponsorship is the first step in undertaking an audit, as it both legitimizes the exercise, and confirms its importance to the organisation.

- Audits should be preceeded by meetings with the organisation to understand the issues needing exploration. Questions should be developed in line with the specific aims of the audit.

- The audit should be immediately followed by a report that is shared with the Boardlevel sponsor, followed by the members of staff for whom the results are relevant.

- When staff participate in identifying the issues, they will engage more enthusiastically in organisational development programmes that are aimed at addressing those issues.

Ethical Approval: This study did not require ethical approval Acknowledgments: The authors would like to thank all the staff of all the organisations in which they have conducted audits for taking part in the interviews and for their openness in answering the audit questions.

Competing interests: We have no competing interests to declare 


\section{References}

Armenakis, A., Brown, S., \& Mehta, A. (2011). Organizational culture: Assessment and transformation. Journal of Change Management, 11(3), 305-328.

Castellano, J. F., \& Lightle, S. S. (2005). Using cultural audits to assess tone at the top. The CPA Journal, 75(2), 6-11.

Davies, H. T., Nutley, S. M., \& Mannion, R. (2000). Organisational culture and quality of health care. Quality in Health Care, 9(2), 111-119.

Department of Health (2012). Long-term conditions compendium of information: Third edition. Retrieved from: <

https://www.gov.uk/government/uploads/system/uploads/attachment data/file/2165 28/dh 134486.pdf> [Accessed 14 February 2017].

Fletcher, B., \& Jones, F. (1992). Measuring organizational culture: The cultural audit. Managerial Auditing Journal, 7(6), 30-36.

Jung, T., Scott, T., Davies, H. O., Bower, P., Whalley, D., McNally, R., \& Mannion, R. (2009). Instruments for Exploring Organizational Culture: A Review of the Literature. Public Administration Review, 69(6), 1087-1096. doi:10.1111/j.1540-6210.2009.02066.x

Lightle, S. S., Baker, B., \& Castellano, J. F. (2009). The Role of Boards of Directors in Shaping Organizational Culture. CPA Journal, 79(11), 68-72.

Mannion, R., Davies, H., Konteh, F., Jung, T., Scott, T., Bower, P., Whalley, D., McNally, R., \& McMurray, R., (2008). Measuring and Assessing Organisational Culture in the NHS (OC1) National Co-ordinating Centre for the National Institute for Health Research Service Delivery and Organisation Programme (NCCSDO).

May, D. (2014). Cultural audit as a means of uncovering unconscious biases and other barriers to diversity within organisations. Governance Directions, 66(2), 89. 
McHugh, M. (1998). Rationalization as a key stressor for public sector employees: an organizational case study. Occupational medicine, 48(2), 103-112.

Mitra, M., Dopson, S., Brankin, P., \& Hoff, T. (2017). Leading together: Collaboration among senior healthcare executives. British Journal of Healthcare Management, 23(1), 12-16.

Powell, A. and Davies, H. (2016). Managing doctors, doctors managing. Research Report, Nuffield Trust. Retrieved from: < https://www.nuffieldtrust.org.uk/files/2017-

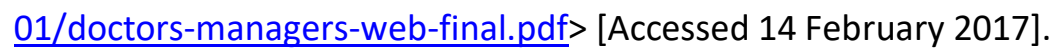

Sanchez, P. M. (2011). Organizational culture. The IABC Handbook of Organizational Communication: A Guide to Internal Communication, Public Relations, Marketing, and Leadership, 11, 28.

Schein, E. H. (2010). Organizational culture and leadership (Vol. 2). John Wiley \& Sons.

Schorg, C. A., Raiborn, C. A., \& Massoud, M. F. (2004). Using a "culture audit" to pick M\&A winners. Journal Of Corporate Accounting \& Finance (Wiley), 15(4), 47-55.

Scott, T., Mannion, R., Davies, H., \& Marshall, M. (2003). The quantitative measurement of organizational culture in health care: a review of the available instruments. Health services research, 38(3), 923-945.

Testa, M. R., \& Sipe, L. J. (2013). The Organizational Culture Audit: Countering Cultural Ambiguity in the Service Context. Open Journal of Leadership, 2(02), 36.

Wilkins, A. L. (1983). The culture audit: A tool for understanding organizations. Organizational dynamics, 12(2), 24-38. 
1. How are things at present in (the organisation) for:
a. You?
b. Your colleagues?
c. Your stakeholders?

2. How are communications and relations in (the organisation)? 